\title{
NORM from the monazite cycle and from the oil and gas industry: Problems and tentative solutions
}

\author{
A.S. Paschoa \\ Laboratório de Radioecologia e Mudanças Globais (LARAMG), Universidade do Estado do \\ Rio de Janeiro (UERJ), Pavilhão Haroldo Lisboa da Cunha, Subsolo, Rua São Francisco \\ Xavier, 524. Maracanã, Rio de Janeiro, RJ 20550-013, Brazila \\ and \\ Instituto de Radioproteção e Dosimetria (IRD), Comissão Nacional de Energia \\ Nuclear (CNEN), Av. Salvador Allende s/n ${ }^{\circ}$, Recreio dos Bandeirantes, Rio de Janeiro, \\ RJ 22780-160, Brazil
}

\begin{abstract}
Naturally occurring radioactive material (NORM) associated with monazite had its origin before the $20^{\text {th }}$ century. The volume and complexity of monazite NORM wastes increased as the industrial applications of monazite also increased. During and after the WWII the diversified uses of thorium turned monazite into an important commodity. At the end of the $20^{\text {th }}$ century the production of oil and gas from offshore platforms in continental shelves increased remarkably. Hundreds of millions of $\mathrm{m}^{3}$ of produced water from the oil and gas industry, containing NORM wastes and other byproducts, are discharged into the oceans every year. E\&P processes mobilize the natural occurring radio-nuclides extant in the oil and gas reservoirs. A wide range of concentrations of ${ }^{238} \mathrm{U}$ and ${ }^{232} \mathrm{Th}$ and their respective progenies, mainly ${ }^{226} \mathrm{Ra},{ }^{222} \mathrm{Rn}$ and ${ }^{210} \mathrm{~Pb}$ (from the ${ }^{238} \mathrm{U}$ series), and ${ }^{228} \mathrm{Ra}$ and ${ }^{228} \mathrm{Th}$ (from the ${ }^{232} \mathrm{Th}$ series) appear in tube scales and sludge. The radium isotopes in NORM wastes generated in the monazite cycle become more bio-available than those isotopes found in wastes from the oil and gas industry. This work discusses some of the problems arising from the existence of monazite cycle and oil and gas industry NORM wastes, and proposes a tentative solution.
\end{abstract}

\section{INTRODUCTION}

Two industrial activities which produce Naturally Occurring Radioactive Materials (NORM) as byproducts have quite different histories. The monazite cycle and the oil and gas industry both started long time ago, and were developed in independent ways. The two may touch each other, however, in the foreseeable future.

The monazite cycle started two centuries ago, well before the discovery of the phenomenon of radioactivity, when a mixture of thorium, lanthanum and cerium was first employed to impregnate fabric bags used in gas lamps to enhance the flame brightness. At that time nobody had any idea that the remnants of those bags would become NORM, or what NORM was. In the $20^{\text {th }}$ century thorium started being separated from monazite to produce substances used in medicine, like thorotrast (an X-ray contrast substance containing $\mathrm{ThO}_{2}$ ). The beginning of the Second World War (WWII) saw an increase in applications of monazite from kerosene lamps using fabric bags impregnated by thorium nitrate to small flints used in wind resistant lighters widely adopted by army soldiers, mariners, and air force personnel to light their cigarettes. At the end of WWII and in subsequent years monazite had become a strategic commodity not only because the extraction of some rare earth compounds used in several industries, but also due to the possibility of using thorium in the planned breeder nuclear reactor. Late in the years 1960s the breeder lost momentum, and monazite was extracted and processed mostly to obtain its rare earth and other compounds widely used in sophisticated products like the then new color TV, modern airplanes, and spacecrafts [1]. 
The current oil and gas industry has been established in the last 200 years. An oil well drilled in the United States in middle $19^{\text {th }}$ century is usually considered to be the first oil well ever drilled. The $20^{\text {th }}$ century saw a remarkable increase in the use of oil and gas. Moreover, the WWII stressed the dramatic importance of the oil and gas reserves, as well as the control of such reserves and the means of E\&P.

The main radionuclides which appear in scales are mostly due to the co-precipitation of radium isotopes with barium sulfate added to the production water. However, the ultimate origin of the ${ }^{226} \mathrm{Ra}$ and ${ }^{228} \mathrm{Ra}$, which appear in those scales is still object of debate. It has been suggested that there is a correlation between the age of petroleum and the ${ }^{238} \mathrm{U}$ and ${ }^{232} \mathrm{Th}$ concentrations found in the organic material from which the petroleum is originated [2]. There is not, however, any experimental data to confirm or not such hypothesis so far.

The monazite cycle leave behind remnants containing NORM with combined ${ }^{226} \mathrm{Ra}$ plus ${ }^{228} \mathrm{Ra}$ activities concentrations which reach levels as high as $10^{4} \mathrm{kBq} \cdot \mathrm{kg}^{-1}$. These NORM wastes from the monazite cycle result from grinding and chemical processes, which make these radium isotopes more bio-available than those resulted from non chemical processes [3]. This is the case, for example of the NORM wastes which appear in the oil and gas industry. A wide range of concentrations of ${ }^{238} U$ and ${ }^{232} \mathrm{Th}$ and their respective progenies, mainly ${ }^{226} \mathrm{Ra},{ }^{222} \mathrm{Rn}$ and ${ }^{210} \mathrm{~Pb}$ (from the ${ }^{238} \mathrm{U}$ series), and ${ }^{228} \mathrm{Ra}$ and ${ }^{228} \mathrm{Th}$ (from the ${ }^{232} \mathrm{Th}$ series) appear in tube scales and sludge. While ${ }^{226} \mathrm{Ra}$ activity concentrations in scales and sludge range from 10 to $1,000 \mathrm{kBq} \cdot \mathrm{kg}^{-1}$; for ${ }^{228} \mathrm{Ra}$ and ${ }^{228} \mathrm{Th}$ the range is from 1 to $100 \mathrm{kBq} \cdot \mathrm{kg}^{-1}$. Radium sulfates are the most common chemical form found in the NORM wastes from the oil and gas industry.

This work will discuss some of the problems arising from the existence of NORM wastes from the monazite cycle and from the oil and gas industry, and will propose some tentative solutions for those problems.

\section{DATA ON NORM FROM THE MONAZITE CYCLE}

Most of the NORM wastes from the monazite cycle are in the form of cake II (Th and U oxides), better known as "torta II in Portuguese - (or cake II)", and mesothorium (Ba, $\mathrm{Ra} \mathrm{SO}_{4}$ ). These NORM wastes result from the magnetic separation and chemical processing of monazite concentrates which leads to torta II and mesothorium wastes. In Brazil alone, the officially recorded total volume of wastes produced by the monazite industry until 2001 was about $10,000 \mathrm{~m}^{3}$ [4]. The monazite cycle left behind remnants containing NORM wastes (torta II and mesothorium) stored in drums kept in warehouses, concrete silos, and trench. The measured ${ }^{226} \mathrm{Ra}$ plus ${ }^{228} \mathrm{Ra}$ activities concentrations in NORM wastes from monazite in Brazil range from $7 \times 10^{3}$ to about $1 \times 10^{4} \mathrm{kBq} \cdot \mathrm{kg}^{-1}$. Moreover, NORM wastes such as those have radium isotopes biologically available because of grinding and chemical processes characteristics of the monazite cycle [3].

Attempts have been made to solve the problems resulting from the NORM wastes from the monazite cycle in Brazil and elsewhere, but to no avail [5-7]. One of the problems of the NORM wastes from the monazite cycle is bioavailability, which in the long run tends to have a distinct probability to reach the food chain. In particular, the ${ }^{226}$ Ra half-life of $1.6 \times 10^{3}$ years poses a long term problem, because of its potential to contaminate surrounding soils and aquifers. Reports of measured external radiation fields of the order of $1 \mu \mathrm{Gy} \cdot \mathrm{h}^{-1}$ or less after the remnants of the monazite cycle have been filled with radioactive free sand are not difficult to find. Before any deactivation or dilution in non-radioactive sand, the external radiation levels at the walls of the torta II drums range from $10^{3}$ to $10^{4} \mu \mathrm{Gy} \cdot \mathrm{h}^{-1}$. Those reports on external radiation levels take into consideration the ${ }^{228} \mathrm{Ra} 6.7$ years half-life and the short term shielding effect of non-radioactive sand. However, in the long term ${ }^{226} \mathrm{Ra}$ tends to migrate to the surfaces of the storage matrix. This fact is usually ignored, because the concentration of this radionuclide from the ${ }^{238} \mathrm{U}$ series in NORM wastes from the monazite cycle is usually one order of magnitude lower than that of ${ }^{228} \mathrm{Ra}$. Figure 1 illustrates the decay and ingrowth curves of the activity ratios ${ }^{228} \mathrm{Th} /{ }^{226} \mathrm{Ra}$ and ${ }^{228} \mathrm{Ra} /{ }^{226} \mathrm{Ra}$, respectively. 


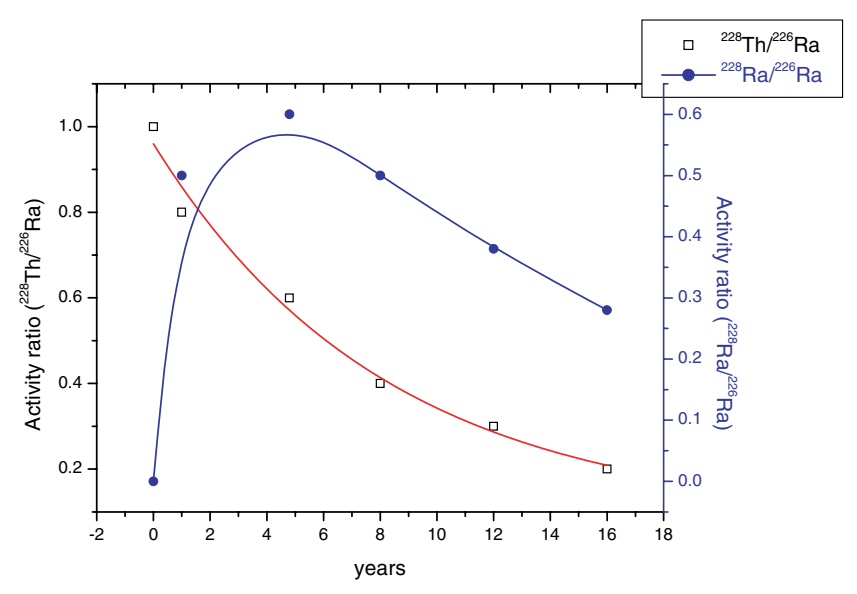

Figure 1. Decay and ingrowth of the activity ratios ${ }^{228} \mathrm{Th} /{ }^{226} \mathrm{Ra}$ and ${ }^{228} \mathrm{Ra} /{ }^{226} \mathrm{Ra}$, respectively.

The fact that at the beginning most of the drums and trenches holding Torta II are sealed does not stand the test of time, because the ${ }^{226}$ Ra activity in the NORM wastes from the monazite cycle. These NORM wastes from the monazite cycle are seldom maintained under the conditions of a well built and managed radioactive waste repository.

Short term shielding does not solve the long term problem, because of the bioavailability of ${ }^{226} \mathrm{Ra}$. The fact that at the beginning most of the drums and trenches holding Torta II are sealed does not stand the test of time. The NORM wastes from the monazite cycle are seldom maintained under the conditions of a well built and managed radioactive waste repository.

Mass increasing with non radioactive material and stabilization of NORM wastes from the monazite cycle containing ${ }^{226} \mathrm{Ra}$ will be part of the tentative solution which will be examined in the paper, but cannot per se solve the problem.

\section{DATA ON NORM FROM THE OIL AND GAS INDUSTRY}

A well known consequence of the E\&P processes of oil and gas is the mobilization of the parent radionuclides of the natural series ${ }^{238} \mathrm{U}$ and ${ }^{232} \mathrm{Th}$, as well as those of their respective progenies. Some of those radionuclides become incrusted inside tubes. The incrustations are better known as radioactive scales. The natural radium isotopes ${ }^{226} \mathrm{Ra}$ (from the ${ }^{238} \mathrm{U}$ series) and ${ }^{228} \mathrm{Ra}$ (from the ${ }^{232} \mathrm{Th}$ series) are likely to appear in the mentioned scales and sludge. These radium isotopes are present in the production water and subsequently in scales and sludge much in the same way as the occurrence of $\mathrm{CaCO}_{3}, \mathrm{BaSO}_{4}$ and $\mathrm{SrSO}_{4}$.

Figure 2 shows typical ranges of ${ }^{226} \mathrm{Ra}$ and ${ }^{228} \mathrm{Ra}$ in scales and sludge in two South American oil and gas production fields. The ${ }^{226} \mathrm{Ra}$ concentrations cover four orders of magnitude for scale and three for sludge. In the case of ${ }^{228} \mathrm{Ra}$ the concentrations cover only one order for scale, but four orders for sludge. The data shown in Figure 2 suggests that there is a wide variation of concentrations of both ${ }^{226} \mathrm{Ra}$ and ${ }^{228} \mathrm{Ra}$ in scale and sludge.

The wide range of ${ }^{226} \mathrm{Ra}$ concentrations found in scales and sludge resulting from E\&P operations is a common problem to be solved by the oil and gas industry. Some attempts have been made to solve this problem with different degrees of success.

In most cases the dose control enforced by the EC Directive 96/29/Euratom [9] is the leit motif which leads to controlling discharges to the marine environment. However, the impact of discharges to the marine environment is quite dependent of the specificity of the water body. Most models used for dose 


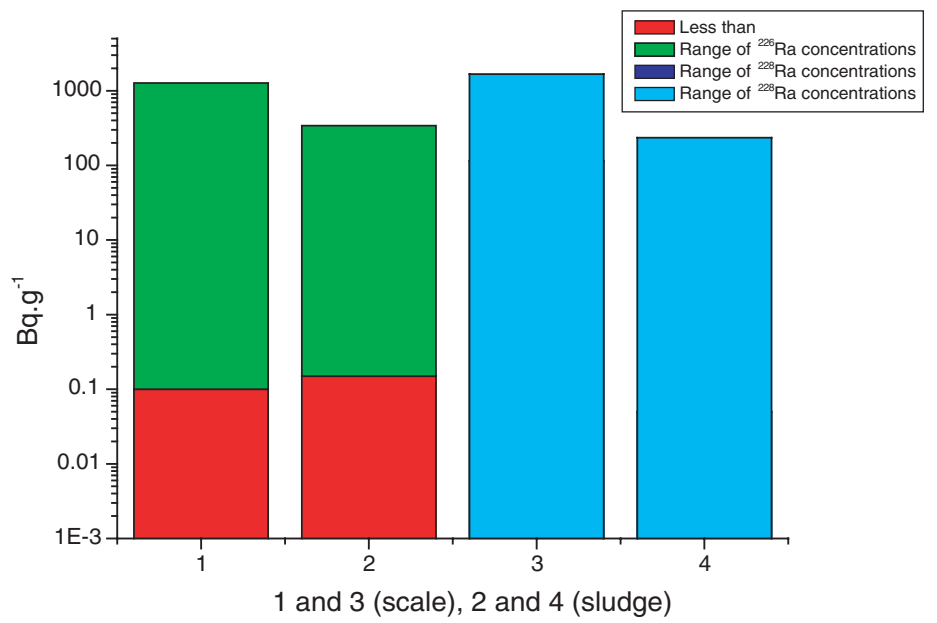

Figure 2. Typical ranges of ${ }^{226} \mathrm{Ra}$ (green \& red) and ${ }^{228} \mathrm{Ra}$ (blue) concentrations in scales $(1 \& 3)$ and sludge $(2 \&$ 4) in two South American oil and gas producing fields. Data taken from references [3] and [8].

estimates related to the discharges of ${ }^{226} \mathrm{Ra}$ into the marine environment ignore the high concentration factor from water to plankton, which lies between $10^{4}$ and $10^{5}$ [10]. Models usually underestimate the dose through specific food chains. The practice of discharging substantial amounts of produced water into the sea has been used often, however, due to the high concentration of ${ }^{226} \mathrm{Ra}$ in plankton, this practice may not be a good idea after all.

\section{A TENTATIVE SOLUTION}

NORM wastes from the monazite cycle containing ${ }^{226} \mathrm{Ra}$ and ${ }^{228} \mathrm{Ra}$ are biologically available and are present in high concentrations. On the other hand, these same radium isotopes in NORM wastes from E\&P cover a wide range of concentrations, but are not biologically available because they did not undergo any chemical processing. In view of these facts, a conceptual use of wastes containing ${ }^{226} \mathrm{Ra}$ and ${ }^{228}$ Ra to make Shielding NORM Brick Blocks (SNBB) was presented elsewhere [3].

The SNBB may be turned into a practical solution for the NORM wastes which appear as byproducts in the monazite cycle, and in the oil and gas industry.

The rationale behind this tentative solution is to turn a high activity concentration $C_{R a 226}$ into a much lower activity concentration $C_{R a 226}^{\prime}$ as illustrated below.

$$
C_{\text {Ra226 }}>E C L \rightarrow C_{R a 226}^{\prime}<E C L
$$

where $E C L$ is the exempt concentration level.

Let be $C_{i}=A_{i}(B q) / m(k g)$ the activity concentration with $i=1$ for ${ }^{226} \mathrm{Ra}$ and $i=2$ for ${ }^{228} \mathrm{Ra}$ in incrustation (scale).

If $C_{i}>10 \mathrm{kBq} \cdot \mathrm{kg}^{-1}$, the aim is to achieve a ${ }^{226} \mathrm{Ra}$ or a ${ }^{228} \mathrm{Ra}$ concentration $C_{i}^{\prime}<10 \mathrm{kBq} / \mathrm{kg}$, after cleaning the tubes which had ${ }^{226} \mathrm{Ra}$ or ${ }^{228} \mathrm{Ra}$ contaminated scales.

To do so a mass $M$ of material (for treatment, dilution and stabilization) is added to the wastes produced after cleaning the tubes to obtain a concentration $C_{i}^{\prime}=A_{i} /(m+M)$. Once the concentration $C_{i}^{\prime}<10 \mathrm{kBq} / \mathrm{kg}$ is chosen as a goal, the ratio $M / m$ can be determined, that means the mass $M$ to be added to the wastes becomes known. Details of the procedure can be seen elsewhere [3].

Figure 3 shows frequency distributions of the ${ }^{226} \mathrm{Ra}$ and ${ }^{228} \mathrm{Ra}$ activity concentrations in scales before any treatment, as measured in a tube storage site.

After treatment, the corresponding frequency distributions would be as shown in Figure 4. 

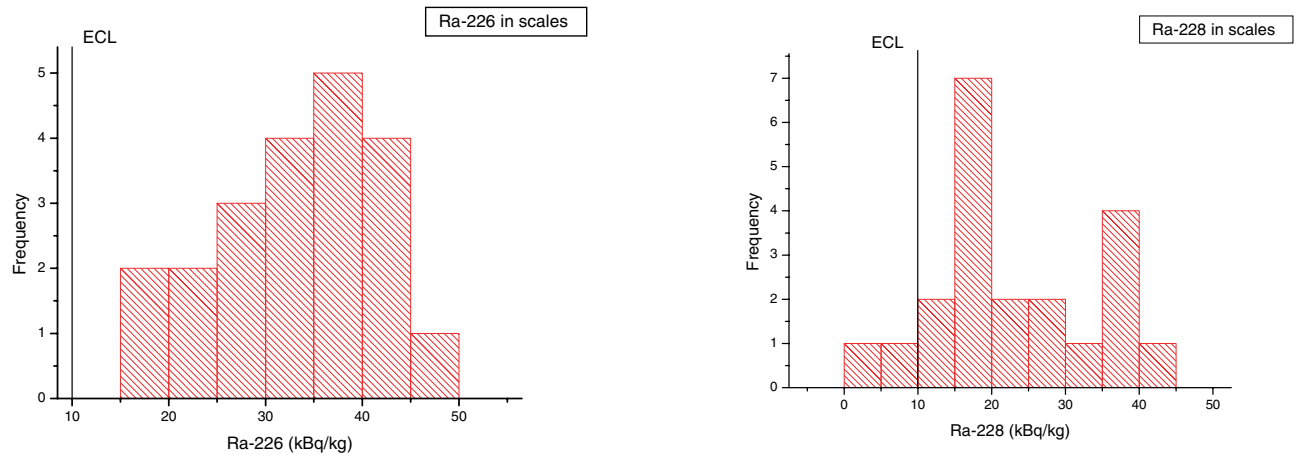

Figure 3. Graphs of the frequency distributions of ${ }^{226} \mathrm{Ra}$ and ${ }^{228} \mathrm{Ra}$ activity concentrations in scales before any treatment.
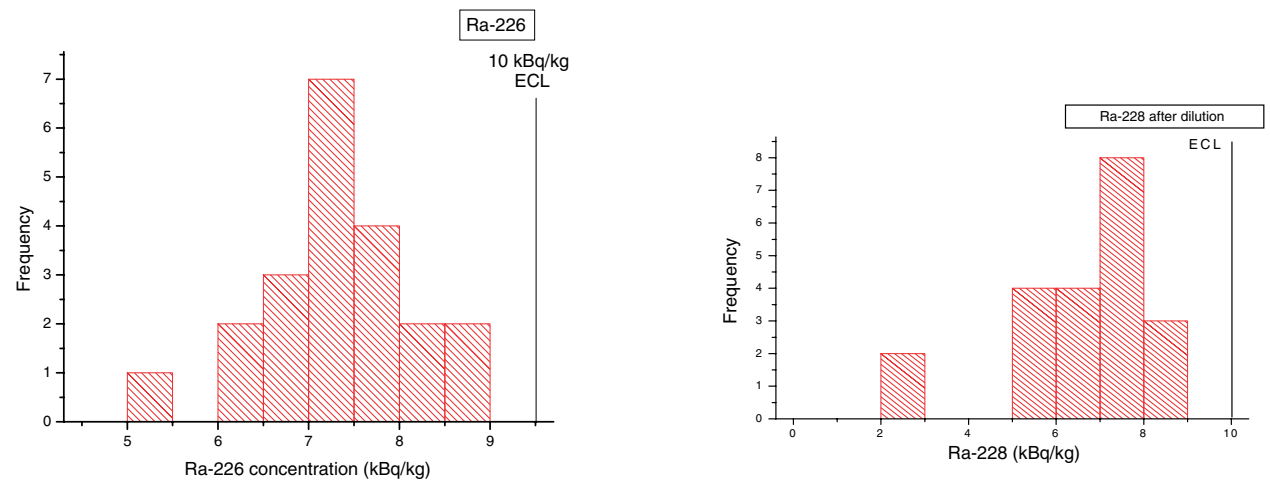

Figure 4. Simulated graphs as the frequency distributions of ${ }^{226} \mathrm{Ra}$ and ${ }^{228} \mathrm{Ra}$ activity concentrations shown in Figure 3 would become after treatment.

The concept presented here may be helpful to take care of the NORM wastes (such as radioactive scales and sludge) which will result from cleaning tubes and equipment used in the E\&P operations in the oil industry.

\section{CONCLUSIONS}

The large volume NORM wastes (non-biologically available) from the oil \& gas industry may be used to decrease the concentration of NORM wastes (biological available) from the monazite industry, after being transformed in SNBB.

The SNBB concept can de used in many different situations, but standardization will facilitate its use as shielding material. Higher radioactive wastes, even from the nuclear industry, can be shielded by SNBB in a low level radioactive repository. The advantages of this tentative solution merit to be further discussed.

\section{References}

[1] Paschoa, A.S., The Monazite cycle in Brazil: past, present and future, Actinide Processing Methods and Materials (B. Mishra and W. A. Averill (Eds. 1994) The Minerals, Metals \& Materials Society, Pennsylvania, pp. 323-338. 
[2] Paschoa, A.S., Naturally Occurring Radioactive Materials (NORM) and petroleum origin, Applied Radiation and Isotopes, 48 (1997) pp. 1391-1396.

[3] Paschoa, A.S., Godoy, J.M., Matta, L.E.S.C. and Evangelista, H., 2008. Conceptual Use of NORM as Primary Shielding for Radioactive Wastes, $5^{\text {th }}$ International Symposium on Natural Occurring Radioactive Material, Seville, Spain, March 19 $19^{\text {th }}-22^{\text {nd }}, 2007$, R. Garcia-Tenorio Ed. (International Atomic Energy Agency, Vienna, 2008) In Press.

[4] Comissão Nacional de Energia Nuclear (CNEN), Ministério de Ciência e Tecnologia (MCT), 2001. Rejeitos Radioativos, 2001. In Portuguese.

[5] Briquet, C.M., Cipriani and Ferreira, A.C., "Soil Contamination in a Rural Site Used for Rare Earth Industry By-product Disposal", Naturally Occurring Radioactive Materials (NORM IV), IAEA-TECDOC-1472, (International Atomic Energy Agency, Vienna, 2004).

[6] Da Costa Lauria, D. and Rochedo, E.R.R., The legacy of monazite processing in Brazil, Radiation Protection Dosimetry, 114 (2005) pp. 546-550.

[7] Pillai, P.M.B., Naturally Occurring Radioactive Materials (NORM) in the Extraction and Processing of Rare Earths, $5^{\text {th }}$ International Symposium on Natural Occurring Radioactive Material, Seville, Spain, March $19^{\text {th }}-22^{\text {nd }}, 2007$, R. Garcia-Tenorio Ed. (International Atomic Energy Agency, Vienna, 2008) In Press.

[8] Canoba, A., Gnoni, G. and Truppa, W., NORM measurements in the oil and gas industry in Argentina, $5^{\text {th }}$ International Symposium on Natural Occurring Radioactive Material, Seville, Spain, March $19^{\text {th }}-22^{\text {nd }}, 2007$, R. Garcia-Tenorio Ed. (International Atomic Energy Agency, Vienna, 2008) In Press.

[9] European Council, Directive 96/29/1996. Euratom Laying Down Basic Safety Standards for the Protection of the Health of Workers and the General Public against the Dangers Arising from Ionizing Radiation, Official Journal L 159, Brussels.

[10] Paschoa, A.S., Baptista, G.B., Wrenn, M.E. and Eisenbud, M.M., Dosimetry of natural and man-made alpha emitters in plankton, International Symposium on the Impacts of Radionuclide Releases into the Marine Environment, 6-10 October, 1980 (International Atomic Energy Agency, Vienna, IAEA-SM-248/140, 1981) pp. 695-718. 